\title{
Haemodynamic and humoral responses to chronic ketanserin treatment in essential hypertension
}

\author{
ROBERT FAGARD, ROBERTO FIOCCHI, PAUL LIJNEN, JAN STAESSEN, \\ EMMANUEL MOERMAN, ANDRÉ DE SCHAEPDRYVER, ANTOON AMERY \\ From the Hypertension and Cardiovascular Rehabilitation Unit, Department of Pathophysiology, University of \\ Leuven, Leuven, and Heymans Institute of Pharmacology, University of Ghent, Ghent, Belgium
}

SUMMARY Ketanserin (120 mg/day) or placebo was given orally to 14 patients with mild to moderate essential hypertension according to a double blind crossover protocol, each treatment period lasting six weeks. Resting intra-arterial pressure in the recumbent position was reduced from 150/84 to 141/77 $\mathrm{mm} \mathrm{Hg}$; the hypotensive effect persisted throughout an uninterrupted graded exercise test to the point of exhaustion. The haemodynamic effects were similar at rest and during exercise. Overall, systemic vascular resistance decreased by $14 \%$, heart rate fell by $5 \%$, but stroke volume and cardiac output increased. Mean pulmonary arterial pressure and capillary wedge pressure were not significantly affected, but pulmonary vascular resistance decreased by $15 \%$.

The pressor response to methoxamine was significantly reduced by ketanserin. Both plasma noradrenaline and adrenaline concentrations increased, plasma renin activity and angiotensin II concentration decreased, and plasma aldosterone concentration was unchanged.

The data indicate that ketanserin induces arteriolar dilatation, possibly related to an alpha-1antagonistic action and to a reduced circulating angiotensin II concentration. The haemodynamic response is complex, and an increase in cardiac output limits the hypotensive effect. There is no firm evidence of an effect on venous tone as cardiac filling pressures do not change.

Ketanserin is a new drug which may be of value for treating a variety of cardiovascular diseases. ${ }^{1}$ Benefits have been reported in hypertension,,$^{2-4}$ heart failure, ${ }^{5}$ Raynaud's phenomenon, ${ }^{6}$ and thrombophlebitis. ${ }^{7}$ The drug has high binding affinity for 5-hydroxytryptamine type 2 receptors ${ }^{8}$ and it inhibits the 5hydroxytryptamine induced vasoconstriction of isolated arterial and venous strips of rats and dogs. ${ }^{9}$ Alpha-1-receptor blocking properties have also been found in the rat. ${ }^{10-12}$ Some acute mechanisms of action of ketanserin have been studied in man. The drug inhibits platelet aggregation induced by 5-hydroxytryptamine, ${ }^{13}$ and does not affect the pressor effect of phenylephrine in sodium depleted normotensive subjects ${ }^{14}$ or in hypertensive patients. ${ }^{15}$ Recently, however, Reimann and Frölich have found that ketanserin shifts the dose-response curve of methoxamine towards higher methoxamine doses in normal subjects, point-

Requests for reprints to Dr R Fagard, Laboratorium voor Hartfunctie, Inwendige Ziekten-Cardiologie, AZ Pellenberg, B-3041 Pellenberg, Belgium.

Accepted for publication 26 July 1983 ing to an alpha-1-antiadrenergic activity. ${ }^{16}$ Blood pressure is considerably reduced in hypertensive patients ${ }^{2}{ }^{4}$ and in normotensive subjects during exercise, ${ }^{17}$ owing to a reduction in systemic vascular resistance. ${ }^{4}{ }^{17}$

Chronic administration of ketanserin lowers blood pressure in hypertension, ${ }^{3}$ but the mechanisms have not been studied. To clarify haemodynamic and humoral mechanisms we studied patients with mild to moderate essential hypertension in a randomised placebo controlled double blind crossover trial.

\section{Patients and methods}

Fourteen patients with essential hypertension were studied, and their characteristics are given in Table 1. Each patient gave informed consent. The diagnosis was based on history, physical examination, appropriate laboratory tests, and an intravenous pyelogram. A renal arteriogram was obtained when indicated. The patients remained on their usual diet throughout the study.

After a run in period of about three weeks, during 
Table 1 Characteristics of patients

\begin{tabular}{ll}
\hline Age $(\mathrm{yr})^{\star}$ & $40 \pm 2$ \\
Sex $(\mathrm{M} / \mathrm{F})$ & $12 / 2$ \\
Weight $(\mathrm{kg})^{\star}$ & $74 \cdot 6 \pm 1 \cdot 6$ \\
Electrocardiogram & 11 \\
$\quad$ Normal & 3 \\
$\quad$ Left ventricular hypertrophy & \\
Recumbent blood pressure (cuff method $)^{\star}(\mathrm{mm} \mathrm{Hg})$ & $162 \pm 4$ \\
$\quad$ Systolic & $104 \pm 3$ \\
$\quad$ Diastolic & $122 \pm 10$ \\
Creatinine clearance $(\mathrm{ml} / \mathrm{min})^{\star}$ & $163 \pm 26$ \\
Urinary sodium excretion $(\mathrm{mmol} / 24 \mathrm{~h})^{\star}$ & \\
\hline
\end{tabular}

Data obtained during treatment with placebo.

$\star$ Values are means $\pm S E$

which the patients received placebo, ketanserin (three $40 \mathrm{mg}$ capsules per day) and placebo (three identical capsules a day) were given for six weeks each, according to a randomised crossover double blind protocol. At the end of each period patients underwent haemodynamic investigation in the morning, after the patient had had a light breakfast at home, in a laboratory where the room temperature was $18-22^{\circ} \mathrm{C}$ and humidity $40-60 \%$. The patients took the morning capsule on arrival in the laboratory at about $8.30 \mathrm{am}$. Two patients refused the haemodynamic investigation at the second visit. In the remaining 12 patients the brachial artery was punctured (Vygon, 115.09) twice to measure systolic, diastolic, and mean intra-arterial pressures and to sample arterial blood. In eight patients, of whom five received treatment first and three received placebo first, a venous catheter (SwanGanz, 93.110 5F) was introduced on both occasions into the antecubital vein and positioned in the pulmonary artery to sample mixed venous blood. The venous catheter was positioned so that pulmonary capillary wedge pressure was measured when the balloon near its tip was inflated and pulmonary artery pressure when the balloon was deflated. Pressures were recorded (Mingograph 81) using ElemaSchönander EMT 34 pressure transducers. Uptake of oxygen and output of carbon dioxide were measured continuously by the open circuit method; minute volume and oxygen and carbon dioxide concentrations were determined using a pneumotachograph and a paramagnetic and infrared gas analyser (Siregnost FD, Siemens). The respiratory gas exchange ratio and the ventilatory equivalent for oxygen were calculated. Cardiac output was determined by the direct oxygen Fick method. Systemic vascular resistance was calculated from mean intra-arterial pressures, obtained by electrical damping, and cardiac output, and pulmonary vascular resistance was calculated from mean pulmonary artery and capillary wedge pressures and cardiac output. Heart rate was obtained from the electrocardiogram. Stroke volume was calculated from cardiac output and heart rate.

A first set of measurements was obtained at rest in the recumbent position 30 minutes after the technical procedures. A test for alpha-1-receptor stimulation $\stackrel{5}{C}$ was then performed in eight of the patients. $\overrightarrow{\vec{F}}$ Methoxamine was infused intravenously at rates of $\frac{\text { ? }}{0}$ 200,400 , and $800 \mu \mathrm{g} / \mathrm{min}$ for 5 minutes at each rate. After stopping the drug infusion, 45-60 minutes was $\overline{\bar{c}}$ allowed for its effect to dissipate. All patients were $\overrightarrow{\widetilde{D}}$ seated on the bicycle ergometer and the resting $\stackrel{\circ}{\circ}$ measurements were obtained 10 minutes later. A के graded, uninterrupted exercise test was then started at $\overrightarrow{0}$ a work load of $10 \mathrm{~W}$ for 1 minute, and the load was increased by $10 \mathrm{~W}$ every minute until the patients were $\vec{\omega}$ exhausted. At one third and two thirds of predetermined maximal work load (determined during the run in period) the work load was maintained for 4 minutes to allow steady state haemodynamic measurements and $T$ blood samples to be obtained.

Biochemical tests were performed on arterial blood. Plasma renin activity was determined by the method of Fyhrquist and Puutula ${ }^{18}$; plasma angiotensin II and plasma aldosterone concentration as described by $\mathbb{D}$ Lijnen $e t a l,{ }^{19}{ }^{20}$ and plasma lactate concentration by an enzymatic method. ${ }^{21}$ Plasma noradrenaline and plasma adrenaline concentrations were measured according to $\vec{\bullet}$ the method of da Prada et al. ${ }^{22}$ Plasma concentrations of ${ }^{\infty}$ ketanserin were determined by Janssen Pharmaceutica using high pressure liquid chromatography (method to be published).

\section{STATISTICAL ANALYSIS}

Treatment with ketanserin and placebo are compared $\cong$ using either paired $t$ tests or three way analysis of $\overrightarrow{\overrightarrow{0}}$ variance with treatment, subjects, and levels of activity 3 (or the infusion rate of the alpha agonist) and their interactions considered as sources of variance. For the latter analysis only the effects of treatment and the interactions between treatment and level of physical activity (or infusion rate of the alpha agonist) are used; $\frac{7}{\sigma}$ the significance of the difference between ketanserin 3 and placebo data at a given level of activity or at a given infusion rate was assessed using the residual mean square from the analysis of variance. (The $F$ value $\mathrm{O}$ refers to the effect of treatment and $\mathrm{Fi}$ to the interaction between treatment and levels of activity.)

For plasma renin activity and plasma angiotensin II, aldosterone, noradrenaline, and adrenaline concentra- $\sigma$ tions, the statistical analysis was performed on the $\log \tilde{O}^{\circ}$ values since their distribution was closer to Gaussian; the geometric mean and range are therefore given. Other values are given as mean $\pm \mathrm{SE}$.

\section{Results}

EFFECT OF KETANSERIN ON MAXIMUM EXERCISE CAPACITY

During treatment with ketanserin the mean total $\frac{\rho}{\mathbb{D}}$ exercise time was $1423 \pm 84 \mathrm{~s}$, which was not signifi- $\frac{\varrho}{\sigma}$ 
cantly different from the value obtained during treatment with placebo $(1429 \pm 96 \mathrm{~s})$. The highest oxygen uptake was $2 \cdot 18 \pm 0 \cdot 16 \mathrm{l} / \mathrm{min}$ with placebo and $2 \cdot 21 \pm 0 \cdot 19$ with ketanserin, and the difference was not significant (NS). At the final work load during placebo treatment the mean values $( \pm S D)$ of respiratory gas exchange ratio, respiratory equivalent for oxygen, and arterial $\mathrm{pH}$ were $1.03 \pm 0.02,33 \cdot 8 \pm 1 \cdot 4$, and $7 \cdot 32 \pm 0.02$ respectively; the values during treatment with ketanserin $(1.04 \pm 0.02,32.8 \pm 1.6$, and $7 \cdot 31 \pm 0.02$ respectively) were not significantly different. Plasma lactate concentration was measured 1,3 , and $5 \mathrm{~min}$ after stopping exercise; the mean of the highest of the three values obtained was $7.9 \pm 0.9 \mathrm{mmol} / \mathrm{l}(71 \pm 8 \mathrm{mg} /$ $100 \mathrm{ml}$ ) during treatment with placebo and $8 \cdot 8 \pm 1 \cdot 2$ $\mathrm{mmol} / \mathrm{l}(79 \pm 11 \mathrm{mg} / 100 \mathrm{ml})$ during ketanserin treatment (NS).

\section{EFFECT OF KETANSERIN ON SYSTEMIC} HAEMODYNAMICS

The overall analysis of resting and exercise data, using three way analysis of variance is presented in Fig. 1-3. For comparison with other studies which report only resting data we have given resting data separately (Table 2).

\section{Data at rest}

Table 2 summarises the haemodynamic data after 30 min of rest supine. Ketanserin reduced brachial artery pressure by $9 / 7 \mathrm{~mm} \mathrm{Hg}$ owing to a reduction in systemic vascular resistance $(p<0.01$ in each case). Heart rate was unchanged, stroke volume increased $(p<0.05)$, but the increase in cardiac output was not significant.

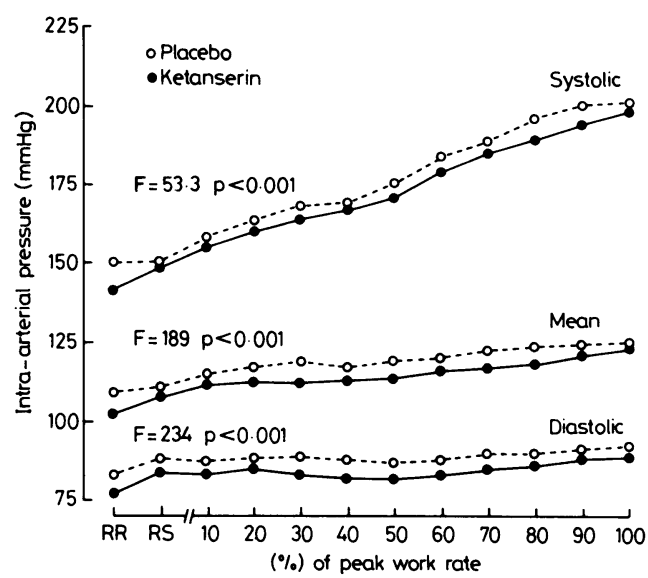

Fig. 1 Systolic, diastolic, and mean intra-arterial pressures at rest in the recumbent position $(R R)$, at rest sitting $(R S)$, and at various levels of exercise, expressed as a percentage of peak work rate, during placebo and during ketanserin treatment. The $F$ value refers to the effect of treatment; there were no significant interactions between the effect of treatment and the levels of physical activity $(n=12)$.

\section{Overall data}

Ketanserin reduced overall systolic, mean, and diastolic intra-arterial pressures $(\mathrm{F}=53, \mathrm{p}<0.001$; $\mathrm{F}=189, \mathrm{p}<0.001 ;$ and $\mathrm{F}=234, \mathrm{p}<0.001$ respectively). (Fig. 1). There were no significant interactions between the effect of treatment and the level of activity (Fi $\leqslant 1 \cdot 0 ; \mathrm{NS}$ ). The mean overall effect was a decrease of $4.4 \mathrm{~mm} \mathrm{Hg}$ for both systolic and diastolic intraarterial pressures and $4.2 \mathrm{~mm} \mathrm{Hg}$ for mean intraarterial pressure.

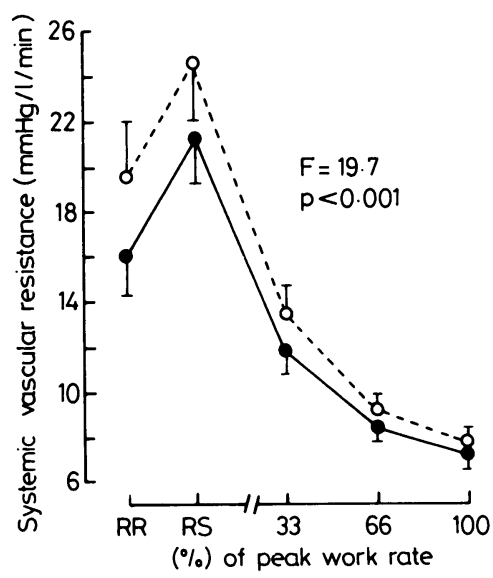

Fig. 2 Cardiac output and systemic vascular resistance at rest, in the recumbent position $(R R)$, at rest sitting $(R S)$, and at various levels of exercise, expressed as a percentage of peak work rate, during placebo and during ketanserin treatment. The $F$ value refers to the effect of treatment; there were no significant interactions between the effect of treatment and the levels of physical activity $(n=8)$. Values are means $\pm S E$. 
Table 2 Systemic haemodynamic effects of ketanserin at rest in the recumbent position

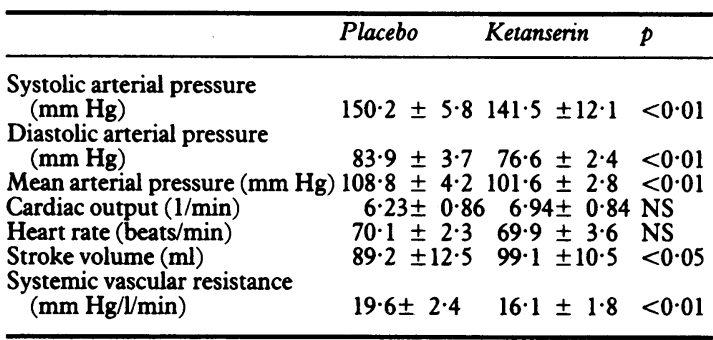

Values are the means of eight observations \pm SE. The $p$ value is derived from three way analysis of variance.

NS, not significant.

Ketanserin reduced systemic vascular resistance $(\mathrm{F}=20 ; \mathrm{p}<0.001)$, increased cardiac output $(\mathrm{F}=13$; $\mathrm{p}<0.01)$ and stroke volume $(\mathrm{F}=21 ; \mathrm{p}<0.001)$, but reduced heart rate $(F=30 ; p<0.001)$ (Fig. 2 and 3 ). There were no significant interactions between the effect of treatment and the level of activity $(\mathrm{Fi} \leqslant 2 \cdot 4$; NS). The mean overall changes were a $14 \%$ decrease in systemic vascular resistance, a 7\% increase in cardiac output, an $11 \%$ increase in stroke volume, and a $5 \%$ decrease in heart rate. The change in cardiac output was based on a decreased difference in arteriovenous oxygen content $(\mathrm{F}=40 ; \mathrm{p}<0.01)$ with unchanged oxygen uptake $(F=1 \cdot 4$; not significant $)$.

\section{Effect of ketanserin on pressures in the right heart and on pulmonary haemodynamics}

The following mean pressures were recorded during treatment with placebo: right atrial pressure $2 \cdot 8 \pm 0.9$ $\mathrm{mm} \mathrm{Hg}$; right ventricular pressures $24 \cdot 7 \pm 2 \cdot 8 / 4 \cdot 2 \pm 0 \cdot 8$ $\mathrm{mm} \mathrm{Hg}$; mean pulmonary artery pressure $12 \cdot 8 \pm 1 \cdot 8$, and pulmonary capillary wedge pressure $7.0 \pm 1.5 \mathrm{~mm}$ $\mathrm{Hg}$. Ketanserin did not affect any of these pressures $(p \geqslant 0 \cdot 2)$.

Table 3 summarises the overall data for mean pulmonary artery pressure and mean pulmonary capillary wedge pressure, which were not significantly affected by ketanserin $(F<1 \cdot 0)$. Pulmonary vascular resistance was reduced $(F=7 \cdot 5 ; p<0 \cdot 01)$.

\section{Effect of ketanserin on the pressor response to alpha receptor stimulation}

Fig. 4 shows that the effect of the alpha receptor agonist methoxamine on systolic intra-arterial pressure during ketanserin treatment was reduced compared with placebo $(F=9.7 ; p<0.01)$. Also the interaction between the effect of ketanserin and the infusion rates of methoxamine $(\mathrm{Fi}=10 \cdot 2 ; \mathrm{p}<0.01)$ was significant. The increase in systolic intra-arterial pressure with methoxamine was significantly reduced during ketanserin treatment at the highest rate of infusion. Methoxamine, $800 \mu \mathrm{g} / \mathrm{min}$, increased systolic intraarterial pressure by $33 \mathrm{~mm} \mathrm{Hg}$ during placebo and by $22 \mathrm{~mm} \mathrm{Hg}$ during ketanserin $(\mathrm{p}<0 \cdot 01)$.

\section{Effect of ketanserin on the renin angiotensin aldosterone} system and on plasma catecholamine concentrations Plasma renin activity was reduced by ketanserin $(\mathrm{F}=37 ; \mathrm{p}<0.001)$ without interaction with the level of physical activity $(\mathrm{Fi}=0.6 ; \mathrm{NS})$. Also plasma angiotensin II concentration was lower during ketanserin treatment than during placebo $(F=27$;
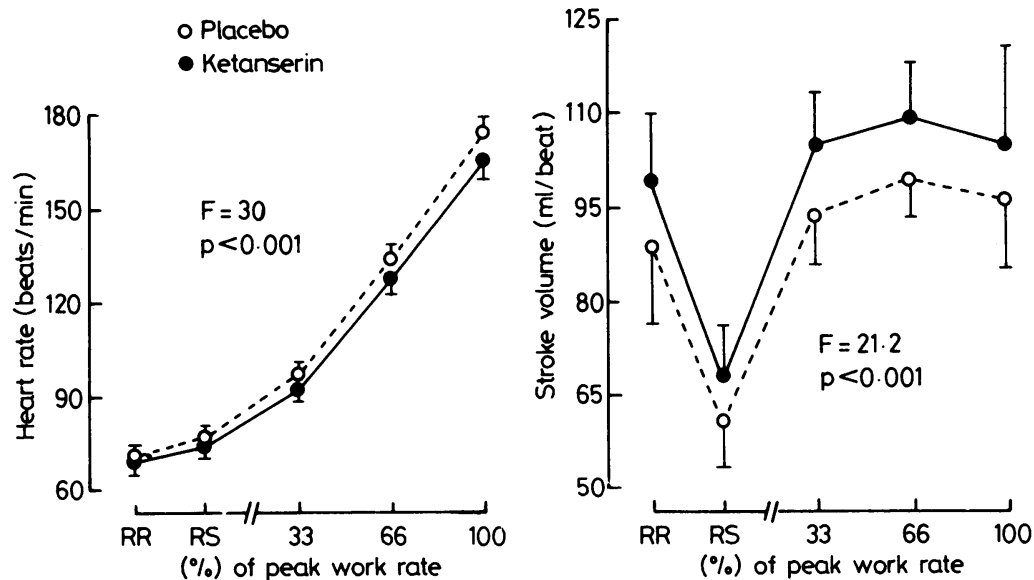

Fig. 3 Heart rate and stroke volume at rest recumbent (RR), at rest sitting $(R S)$, and at various levels of exercise, expressed as a percentage of peak work rate, during placebo $(O)$ and during ketanserin $(O)$ treatment. The $F$ value refers to the effect of treatment; there were no significant interactions between the effect of treatment and the levels of physical activity $(n=8)$. Bars represent means $\pm S E$. 
Table 3 Pulmonary haemodynamic data during treatment with placebo $(P)$ and ketanserin $(K)$ at rest in the recumbent position $(R R)$, at rest sitting $(R S)$, and at $33 \%, 66 \%$, and $100 \%$ of the final work rate. $F$ refers to the effect of treatment and $F i$ to the interaction between treatment and levels of activity

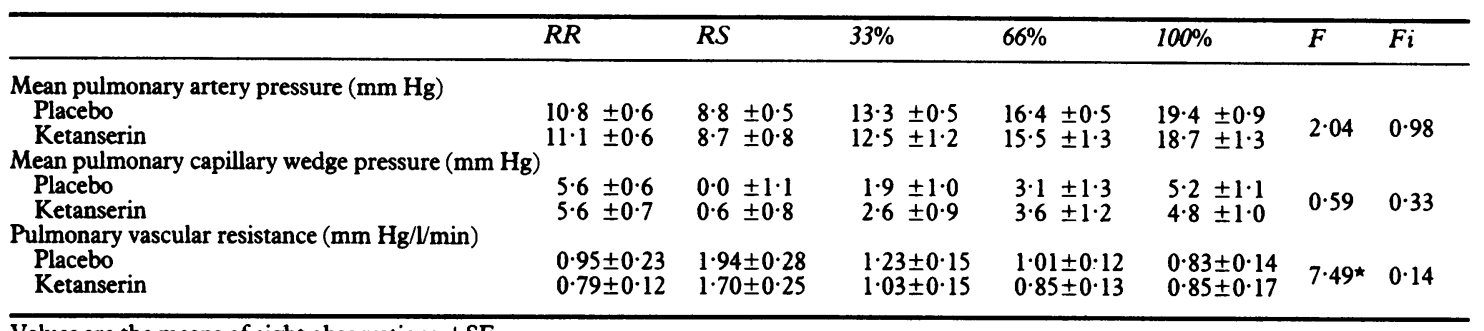

Values are the means of eight observations \pm SE.

${ }^{\star} \mathrm{p}<0.01$; all others NS.

$\mathrm{p}<0.001 ; \mathrm{Fi}=0 \cdot 1 ; \mathrm{NS})$. Plasma aldosterone concentration, however, was not affected ( $F=4.0 ; \mathrm{NS})$ (Fig. 5). Both plasma noradrenaline $(F=16 ; p<0.001)$ and adrenaline concentrations $(F=4.3 ; p<0.05)$ increased with ketanserin treatment, without interaction with the level of physical activity (Fi<1.6; NS) (Fig.6).

\section{Other effects of ketanserin}

Ketanserin increased mean body weight from $74.3 \pm 3.6$ to $75 \cdot 3 \pm 3.6 \mathrm{~kg}(\mathrm{p}<0.05)$.

During treatment with placebo mean haemoglobin concentration was $14.4 \pm 0.4 \mathrm{~g} / \mathrm{dl}$ at rest in the recumbent position, $15 \cdot 1 \pm 0.5 \mathrm{~g} / \mathrm{dl}$ at rest sitting, and $15.3 \pm 0.5,15.5 \pm 0.5$ and $15.5 \pm 0.5 \mathrm{~g} / \mathrm{dl}$ at $33 \%, 66 \%$, and $100 \%$ of the maximum work rate respectively. The concentrations during treatment with ketanserin

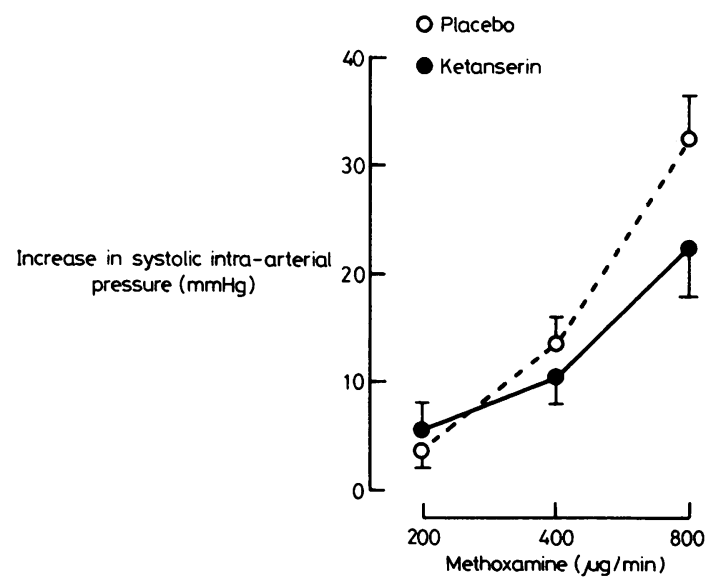

Fig. 4 Increase in systolic intra-arterial pressure at various infusion rates of methoxamine during placebo and ketanserin treatment. Analysis of variance showed a significant interaction between the infusion rate of methoxamine and treatment and $a$ significant difference $(p<0.01)$ at the highest rate of infusion $(n=8)$. Values are means $\pm S E$.
$(14 \cdot 2 \pm 0.5 ; 14 \cdot 7 \pm 0 \cdot 5 ; \quad 14 \cdot 8 \pm 0 \cdot 5 ; \quad 15 \cdot 0 \pm 0.5 ;$ and $15 \cdot 2 \pm 0.5 \mathrm{~g} / \mathrm{dl}$ respectively) were reduced $(\mathrm{F}=61$; $\mathrm{p}<0.001)$. Overall arterial $\mathrm{pH}(\mathrm{F}=0 ; \mathrm{NS})$ and plasma lactate concentration $(\mathrm{F}=1 \cdot 3 ; \mathrm{NS})$ were not significantly affected by ketanserin.

Mean plasma ketanserin concentration was $121 \pm 25$ $\mathrm{ng} / \mathrm{ml}$ at the end of the rest period in the recumbent position and $63 \pm 15 \mathrm{ng} / \mathrm{ml}$ at the maximum work load. Ketanserin was not detectable during treatment with placebo, except in one of the three samples from one patient.

\section{Discussion}

Ketanserin is a new drug which may be of value for treating a variety of cardiovascular diseases. ${ }^{1}$ In order to investigate its mechanisms we studied patients with essential hypertension in a randomised crossover placebo controlled trial. Because of the six weeks' placebo period the study was restricted to patients with mild to moderate hypertension. Indeed, mean cuff blood pressure in the recumbent position during treatment with placebo was $162 / 104 \mathrm{~mm} \mathrm{Hg}$ and intraarterial pressure after 30 minutes' rest in this position was even lower.

Six weeks of oral treatment with a daily dose of 120 $\mathrm{mg}$ of ketanserin significantly reduced systemic vascular resistance both at rest and during exercise, resulting in a lower blood pressure. It is likely that arteriolar dilatation constitutes the primary haemodynamic action of the drug. Acute intravenous administration also lowered vascular resistance significantly in hypertensive patients ${ }^{4}$ and in patients with cardiac failure. The mechanisms responsible for the arteriolar dilatation, however, could be different after acute and after chronic administration. In acute administration the drug did not affect the pressor response to the alpha agonist phenylephrine ${ }^{14}{ }^{15}$ whereas the dose-response curve to methoxamine was shifted. ${ }^{16}$ In the present study the response to methoxamine was reduced 

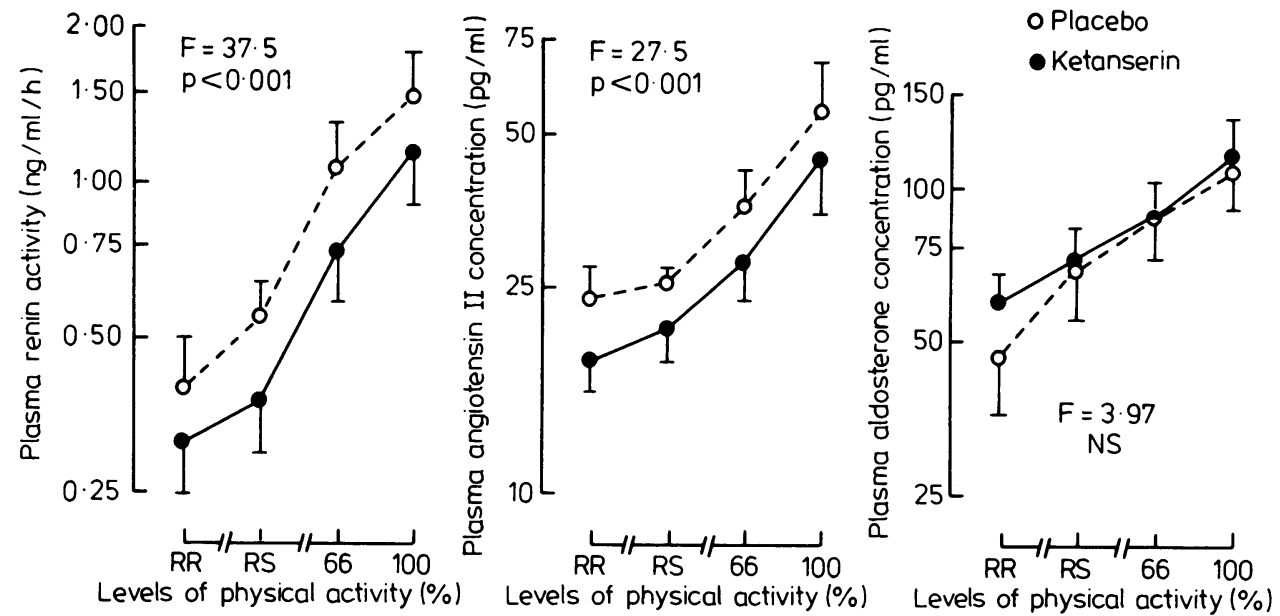

Fig. 5 Plasma renin activity, plasma angiotensin II concentration, and plasma aldosterone concentration at rest in the recumbent position, at rest sitting $(R S)$, and at $66 \%$ and $100 \%$ of peak work rate during placebo and during ketanserin treatment. The $F$ value refers to the effect of treatment; there were no significant interactions between the effect of treatment and the levels of physical activity $(n=12)$. Values are means $\pm S E$.

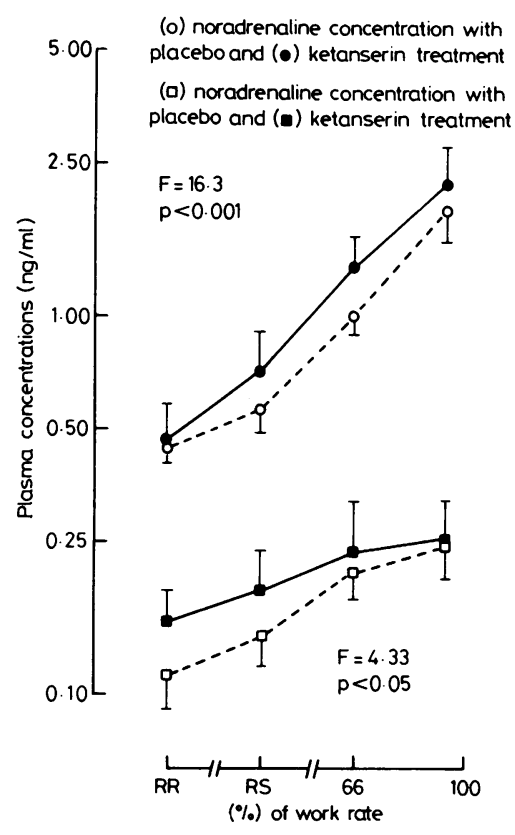

Fig. 6 Plasma noradrenaline and adrenaline concentrations at rest in the recumbent position $(R R)$, at rest sitting $(R S)$, and at $66 \%$ and $100 \%$ of peak work rate, during placebo and during ketanserin treatment. The $F$ value refers to the effect of treatment; there were no significant interactions between the effect of treatment and the levels of physical activity $(n=10)$. Values are means $\pm S E$. during chronic oral treatment of hypertensive patients. This is compatible with alpha-1-antagonist activity. We cannot establish, however, if the antagonistic activity is competitive or non-competitive. Indeed, because of limitations in the pressor rise that can be induced with alpha agonists in humans, full log dose response curves cannot be constructed. Therefore, we cannot find out whether or not a parallel shift of the curve occurs during ketanserin treatment. Various non-specific mechanisms could have interfered such as inhibition of the amplification of alpha receptor agonism by serotonin, ${ }^{9}$ differences in background plasma angiotensin II and plasma noradrenaline concentrations, a lower blood pressure before the alpha agonist test during ketanserin treatment, or a possible reduction of vascular hypertrophy after six weeks of ketanserin treatment. Furthermore, in contrast to observations after acute administration, ${ }^{13}$ the 5hydroxytryptamine induced platelet aggregation was not inhibited during chronic ketanserin treatment of hypertensive patients, ${ }^{23}$ so that involvement of antiserotonergic activity in the antihypertensive effect is unlikely.

Overall, plasma noradrenaline and adrenaline concentrations increased with ketanserin, which probably reflects increased sympathetic tone. This, together with the decreased afterload, may explain the higher stroke volume. Left ventricular filling pressure, as assessed from the pulmonary capillary wedge pressure at rest and exercise, did not change, suggesting that preload was unchanged. Tachycardia did not occur in this and in another chronic study, ${ }^{3}$ and, in fact, 
exercise heart rate was slightly lower during ketanserin treatment. This lower heart rate, with increased plasma catecholamine concentrations, is not yet understood but could suggest an increased vagal tone, as shown in rats. ${ }^{10}$ This implies a possible central action of the drug. Also the decreased circulating angiotensin II concentration may have contributed to the bradycardic effect since angiotensin II increases heart rate..$^{24}$ After acute administration, however, the expected increase in heart rate did occur. ${ }^{4}{ }^{17}$

Overall pulmonary vascular resistance decreased, as occurred after acute administration of ketanserin in patients with heart failure, ${ }^{5}$ suggesting a similar action of the compound on pulmonary and on systemic arterioles. Right atrial pressure, only available at rest, did not change. This implies that venous dilatation did not occur, but does not exclude a new balance between venous pooling of blood and an increased plasma volume, compatible with the higher body weight and the reduced haemoglobin concentration.

Acute administration of ketanserin reduced plasma aldosterone concentration. ${ }^{172}{ }^{25}$ In in vitro studies ${ }^{26} 5$ hydroxytryptamine stimulated the aldosterone release from adrenal slices. The decrease of plasma aldosterone concentration after acute administration of ketanserin could therefore be a direct effect of 5hydroxytryptamine inhibition. During chronic administration, however, this effect of ketanserin was lost. Plasma renin and angiotensin II concentration decreased, which may have contributed to the antihypertensive effect. Fluid retention, as suggested by the increased body weight, may have lowered plasma renin and angiotensin II concentration, but how this apparent suppression of the renin angiotensin system is maintained despite the increase in catecholamine levels and the decreased arterial pressure requires further investigation. It is not clear whether alpha antagonism played a role since alpha receptor blockade has a variable effect on renin. ${ }^{27}$

In conclusion, the haemodynamic pattern during chronic treatment with ketanserin is complex and its mechanisms are poorly understood. The drug reduces systemic vascular resistance, but there is no convincing evidence that it affects venous tone. An alpha-1antagonist action and a reduction in plasma angiotensin II concentration may contribute to the arteriolar dilatation. Increased sympathetic stimulation is shown by the increase in plasma catecholamine concentrations. The increase in cardiac output, owing to an increase in stroke volume, limits the hypotensive effect. The haemodynamic and humoral effects of chronic oral treatment seem to be different from reported changes after acute intravenous administration.

We thank Y Piccart, R Nuyts, L Cockx, J Huysecom, J
Delsupehe, and J Romont for their assistance.

$\mathbf{R}$ Fiocchi received a fellowship for advanced professional training from the Italian Labour Department and the EEC. He is on leave of absence from the Instituto di Ricerche Farmacologiche Mario Negri, Milan, Italy.

This work was supported in part by grants from the Belgian Fund for Medical Research (NFWO). Ketanserin was generously supplied by Janssen Pharmaceutica, Beerse, Belgium.

\section{References}

1 Anonymous. Ketanserin: a selective serotonin antagonist [Editorial]. Lancet 1982; ii: 859.

2 De Crée J, Verhaegen H, Symoens J. Acute blood pressure lowering effect of ketanserin. Lancet 1981; i; 1161-2.

3 De Crée J, Leempoels J, Geukens H, De Cock W, Verhaegen $\mathbf{H}$. The anti-hypertensive effects of ketanserin (R41 468), a novel 5-hydroxytryptamine-blocking agent, in patients with essential hypertension. Clin Sci 1981; 61: $473 \mathrm{~s}-6 \mathrm{~s}$.

4 Wenting GJ, Man in 't Veld AJ, Woittiez AJ, Boomsma F, Schalekamp MADH. Treatment of hypertension with ketanserin, a new selective 5- $\mathrm{HT}_{2}$ receptor antagonist. $\mathrm{Br}$ Med F 1982; 284: 537-9.

5 Demoulin JC, Betholet M, Soumagne D, David JL, Kulbertus HE. 5-HT -receptor blockade in the treatment of heart failure. Lancet 1981 ; i: 1186-8.

6 Stranden E, Roald OK, Krogh K. Treatment of Raynaud's phenomenon with the 5-HT -receptor antagonist ketanserin [Abstract]. $\mathrm{Br} \mathrm{Med} \mathrm{f} \mathrm{1982;} \mathrm{285:} 1069$.

7 De Roose J, Symoens J. Ketanserin in acute superficial thrombophlebitis [Letter]. Lancet 1982; ii: 440-1.

8 Leysen JE, Awouters F, Kennis L, Laduron PM, Vandenberk J, Janssen PAJ. Receptor binding profile of $\mathrm{R} 41$ 468, a novel antagonist at 5-HT, receptors. Life Sci 1981; 28: 1015-22.

9 Van Nueten JM, Janssen PAJ, Van Beek J, Xhonneux R, Verbeuren TJ, Vanhoutte PM. Vascular effects of ketanserin (R41 468), a novel antagonist of 5- $\mathrm{HT}_{2}$ serotonergic receptors. $\mathcal{F}$ Pharmacol Exp Ther 1981; 218: 217-30.

10 Fozard JR. Mechanisms of the hypotensive effect of ketanserin. $\mathcal{F}$ Cardiovasc Pharmacol 1982; 4: 829-38.

11 Kalkman HO, Timmermans PBMWM, Van Zwieten PA. Characterization of the antihypertensive properties of ketanserin (R41 468) in rats. $\mathcal{F}$ Pharmacol Exp Ther 1982; 222: 227-31.

12 Persson B, Hedner T, Henning M. Cardiovascular effects in the rat of ketanserin, a novel 5-hydroxytryptamine receptor blocking agent. $\mathcal{F}$ Pharm Pharmacol 1982; 34: 442-5.

13 De Clerck F, David JL, Janssen PAJ. Serotonergic amplification mechanisms in blood platelets. In: De Clerck F, Vanhoutte PM, eds. 5-Hydroxytryptamine in peripheral reactions. New York: Raven Press, 1982: 83-94.

14 Zoccali C Zabludowski J, Isles CG, Robertson JIS, Fraser R, Ball SG. Effects of ketanserin, a new selec- 
tive serotonin antagonist, on blood pressure and the reninaldosterone system in sodium-depleted normal subjects. Clin Sci 1982; 63: 46.

15 Wenting GJ, Schalekamp MADH. Serotonin (5 HT) and blood pressure, treatment of hypertension with a highly selective 5-HT receptor antagonist. Eur $\mathcal{F}$ Clin Invest 1982; 12 (suppl II): 46.

16 Reimann IW, Frölich JC. Is ketanserin a D receptor antagonist? [Letter]. Lancet 1983; 1: 703-4.

17 Fagard R, Cattaert A, Lijnen P, et al. Responses of the systemic circulation and of the renin-angiotensinaldosterone system to serotonin-antagonism at rest and during exercise in normal man. $\mathrm{Clin}$ Sci (in press).

18 Fyhrquist F, Puutula L. Faster radioimmunoassay of angiotensin I at $37^{\circ} \mathrm{C}$. Clin Chem 1978; 24: 115-8.

19 Lijnen P, Amery A, Fagard R, Katz F. Radioimmunoassay of angiotensin II in unextracted plasma. Clin Chim Acta 1978; 88: 403-12.

20 Lijnen P, Amery A, Fagard R, Corvol P. Direct radioimmunoassay of plasma aldosterone in normal subjects. Clin Chim Acta 1978; 84: 305-14.

21 Bergmeyer HU. Methods of enzymatic analysis. New York: Academic Press, 1974: 1164-472.
22 Da Prada M, Zurcher G. Simultaneous radioenzymatic determination of plasma and tissue adrenaline, noradrenaline and dopamine within the fentomole range. Life Sci 1976; 19: 1161-74.

23 Amery A, Fagard R, Fiocchi R, Lijnen P, Staessen J, Vermylen MJ. Antihypertensive action and serotonininduced platelet aggregation during chronic ketanserin treatment in hypertensive patients. $\mathcal{F}$ Cardiovasc Pharmacol (in press).

24 Nishith SD, Davis LD, Youmans WB. Cardioaccelerator action of angiotensin. Am $\mathcal{F}$ Physiol 1962; 202: 237-40.

25 Wenting GJ, Man in 't Veld AJ, Woittiez AJ, Boomsma F, Schalekamp MADH. Haemodynamic effects of ketanserin, a new selective 5-hydroxytryptamine (serotonin) receptor antagonist, in essential hypertension. Clin Sci (in press).

26 Tait SAS, Tait JF, Bradley JES. The effect of serotonin and potassium on corticosterone and aldosterone production by isolated zona glomerulosa cells of the rat adrenal cortex. Aust f Exp Biol Med Sci 1972; 50: 833-46.

27 Oparil S, Haber E. The renin-angiotensin system. $N$ Engl f Med 1974; 291: 389-401. 